\title{
The implementation of BIM in construction projects
}

\author{
Sergey Sinenko ${ }^{1, *}$, Pavel Hanitsch ${ }^{1}$, Sheroz Aliev ${ }^{1}$, and Mikhail Volovik ${ }^{1}$ \\ ${ }^{1}$ Moscow State University of Civil Engineering, 129337, 26 Yaroslavskoye sh., Moscow, Russia
}

\begin{abstract}
Building Information Modeling Implementation (BIM) is a management task that has undergone major changes. Therefore, identifying the critical success factors in BIM implementation and identifying its implementation challenges in the construction industry is a prerequisite for this change process. The purpose of this research is to understand the construction industry in order to provide a clear understanding of the application of BIM and to provide a suitable way of the mobility of people to implement more comprehensive BIM, which in turn, implements modeling. Building information provides strategies and recommendations for the construction industry. This research, based on a review of previous study, BIM implementation methods and critical success factors in the field of implementation have been discussed, which opens the way for quantitative and qualitative method analysis. Also provides a solid foundation for organizations to make informed decisions in implementing BIM in the body of the organization structure. The main purpose of this research is to identify the factors that are important for the success of BIM implementation. Such factors include BIM potentials and the impact of these potentials on improving the performance of the companies that implement BIM. The research based on a literature review, and presents survey results and significant factors identified on the impacts of BIM implementation and organizational performance improvement.
\end{abstract}

\section{Introduction}

The BIM (Building Information Modeling) is a powerful tool that has taken almost two decades to develop. In the past few years, the use of BIM tools has been under increasing pressure from many architects, engineers, and consultants (AEC industry), so construction companies are now beginning to adopt these innovative ways to increase productivity. One of the technologies that have emerged over the past decade and a half is the creation of information modeling (BIM). This technology has made the design more sophisticated due to the evolution of technologies that support BIM. Currently, the model industry in developed countries can support not only 3D models, but also the areas of construction management as well as planning, cost control, evaluation, safety education and sustainability. This study focuses on identifying the problems / problems you face when adopting BIM in a developing country. Prior knowledge of problems / potential problems can be the difference between successful adoption and the inability to adopt BIM in a timely and cost-effective manner [1].

\footnotetext{
* Corresponding author: sharif.farahmand @gmail.com
} 


\subsection{BIM Definition}

Building Information Modeling (BIM) is not a proprietary product or software. This is an integrated process built on consistent and reliable project information from design to construction and operation [2]. BIM is not just for architects. Implemented in architecture, BIM principles apply to everything that is built, and the advantages of BIM are used by civil engineers as well as architects [3].

BIM is not only 3-D (although it is part of it). BIM allows engineers to more easily predict the performance of projects before they are created; Respond to design changes faster Optimize design with analysis, modeling, and visualization and deliver better building documentation. In addition, this allows extended groups to extract valuable data from the model in order to facilitate earlier decision-making and implementation of economic projects [4]. The building information model is primarily a three-dimensional digital representation of the building and its internal characteristics [5]. It consists of intelligent building components that include data attributes and parametric rules for each object. In addition, BIM provides consistent and coordinated representations and representations of the digital model, including reliable data for each representation. This saves a lot of time for the designer, since each view is coordinated using the model's builtin intelligence [6]. In accordance with the national BIM standard, the building information model is "a digital representation of the physical and functional characteristics of the object and a common knowledge resource for information about the object, which forms a reliable basis for decision-making during its life cycle; defined as existing from the earliest concept to demolition" [7].

BIM or 3D modeling has led to a dramatic change in the AEC industry in technology and processes. The National Committee for Building Information Modeling Standards (NBIMS) in the United States (USA) defines BIM as a digital representation of the physical and functional characteristics of an object [8]. Different people and organizations have different definitions for BIM based on their specific use and different ways of working with BIM. Another definition of BIM proposed by Van Nederwin: "A building information model" that contains complete and sufficient information to support all life cycle processes and that can be directly interpreted by computer applications. Therefore, most of the benefits offered by BIM are included in its definitions. The National Institute of Building Sciences states that "Building Information Modeler (BIM), uses advanced digital technology to create a computable representation of all the physical and functional characteristics of an object and related project/life cycle information, and it is intended to be a repository of information for the owner/operator of the object to use and maintenance throughout the entire life cycle of the facility" [9].

Research shows that BIM (Building Information Modeling) is a critical asset for preconstruction construction through end-of-life operations. Only recently, however, have BIM's benefits for infrastructure construction begun to be recognized and realized [10]. In addition, the benefits of using BIM for infrastructure management include the opportunity to record and detail each maintenance operation. Documents can provide a record for each component in terms of cost and maintenance history [11].

\section{Materials and methods}

\subsection{BIM applications in construction industries}

Building Information Modeling (BIM) is widely seen as a catalyst for innovation and productivity in the construction industry. The BIM can contribute to a more sustainable 
construction process that may in turn help eradicate poverty in developing countries (United Nations Millennium Goals) [12].

The use of BIM in a different area is expanding because researchers realize the potential value of BIM can provide [13]. While the use of BIM for structural and energy analysis with $27 \%$ and $25 \%$ frequencies, respectively, its main use is still in the faster development of 3D geometric models and 3D synchronization with usable frequencies; [13] Has been reported. The use of BIM is not limited to architects and engineers. There are also incentives for owners, facility managers, contractors, and fabricators to use BIM [14].

Many of the important factors that lead to the adoption of BIM in a project are focused on automation in the modeling process, improving the accuracy of construction documents, improving inter-party communication in the design and construction process, automatically reflecting changes in design. All observations after correcting a view and reducing background coordination problems [13]. While many applications of BIM are dedicated to building design, the emphasis is on some other areas, such as the use of BIM in energy modeling, which cannot be referred to as BBIP. A review of the relatively comprehensive literature on BIM and its applications shows that most sources, focusing mainly on planning, design, construction, operation, and energy consumption, with the publication of a more focused archive on energy design and consumption [15].

\subsection{Implementation of BIM in various countries}

\subsubsection{BIM in developed and industrialized countries}

There were no significant changes in building design methods were observed until the midnineteenth century and engineers were used to describe their design with traditional methods (pen, paper, and ruler) [16]. With advances in technology, building materials and mathematics, the design process in the experienced construction industry is undergoing a dramatic and dramatic change. In developed countries, BIM, since its introduction in 1990, has found its place in Architecture, Engineering and Construction (AEC) (Table 1). [17].

In the Nordic countries (Norway, Denmark, Sweden and Finland) where the main producers are the main producers of AEC technology (Tekla, ArchiCAD (Hungarian) and Solibri companies. In these countries, IFC has standards for the proper use of construction technologies). Although there has been no government official for the use of BIM in Northern European countries, the concept of the construction industry seems to have grown significantly in these countries [2].In the United States, the official use of BIM relates to the Office of Public Services. (GSA) that supports BIM third and fourth dimensions. Since 1, GSA has made it mandatory for all projects to use BIM for approval before finalizing a project idea. Today, $5 \%$ of US construction companies are thought to be using BIM to save significant costs on projects. Several US states, universities, and private organizations adopt BIM standards. GSA is actively involved in architectural, engineering and construction conferences, including the AIA-TAP, its annual projects for the AIA-BIM Award nominee [18]. 
Table 1. BIM in developed countries.

\begin{tabular}{|c|c|}
\hline \begin{tabular}{|l|} 
United \\
States of \\
America (USA) \\
BIM Level 3
\end{tabular} & $\begin{array}{l}\text { Known as the leader of BIM movement. } \\
\text { Starting in 1990's with the formation of building SMART, formerly called the } \\
\text { International Alliance for Interoperability (IAI). } \\
\text { The National BIM policy program was introduced in 2003, and later in } 2007 \text { BIM was } \\
\text { mandated in the USA. }\end{array}$ \\
\hline $\begin{array}{l}\text { (UK) } \\
\text { BIM Level } 2\end{array}$ & $\begin{array}{l}\text { In UK, BIM is a term that has become abundant in the design and construction fields over the } \\
\text { past } 20 \text { years. } \\
\text { UK is known as a current world leader in BIM adoption promptness. } \\
\text { UK government in } 2011 \text { published The Government Construction Strategy and announced its } \\
\text { intention to require collaborative 3D BIM on its projects under asset information, documentation } \\
\text { and data being electronic by } 2016 \text {. } \\
\text { UK has a vision in adopting UK Digital Built Britain / UK BIM Level 3. The Digital Built } \\
\text { Britain strategy takes the next step in integrating these digital technologies and use fully } \\
\text { computerized in construction process. }\end{array}$ \\
\hline $\begin{array}{l}\text { Finland } \\
\text { BIM Level } 2\end{array}$ & $\begin{array}{l}\text { The integrated computer-aided building design study have been discussed in Finland since } \\
1983 \text {. } \\
\text { In } 2002 \text {, the } 1 \text { st integrated BIM project HUT }-600 \text { was implemented in Finland. } \\
\text { The government body known as Senate Properties in } 2007 \text { has given a mandate on BIM } \\
\text { requirements in its projects. }\end{array}$ \\
\hline $\begin{array}{l}\text { Australia } \\
\text { BIM Level } 2\end{array}$ & $\begin{array}{l}\text { Building information modelling (BIM) has emerged in Australia, particularly in } 2011 \text { after the } \\
\text { UK Government recognized. The tangible benefits of using BIM and announced a mandate that } \\
\text { requires all central government-funded projects from } 2016 \text { to use a BIM framework. } \\
\text { In February } 2016 \text {, Infrastructure Australia recommended: that Australian government should } \\
\text { make the use of BIM as mandatory for the design of large-scale complex infrastructure projects. } \\
\text { The Department of Planning, Transport and Infrastructure (DPTI) have developed BIM } \\
\text { guidelines for government agencies, consultants and contractors, with the New South Wales' } \\
\text { Health mandating BIM deliverables on all projects over } \$ 30 \text { million. }\end{array}$ \\
\hline & $\begin{array}{l}\text { re Construction and Construction Authority (BCA) began work with the Corenet } \\
\text { (before the BIM), but with its early introduction, its development was delayed. }\end{array}$ \\
\hline $\begin{array}{l}\text { Hong Kong } \\
\text { BIM Level } 2\end{array}$ & $\begin{array}{l}\text { BIM implementation in construction industry in Hong Kong is still in the primary stage in } \\
\text { terms of the scale of application; } \\
\text { The Hong Kong Institute of Building Information Modelling (HKIBIM) was established in } \\
2009 \text {. } \\
\text { program has become mandatory due to resource constraints in the country. }\end{array}$ \\
\hline
\end{tabular}

\section{Results}

\subsection{BIM in Developing Countries}

While many construction projects in developed countries are gradually enforcing BIM, technology development in developing countries is lagging. For example, although BIM is growing slowly in the Middle East, a recent survey found that adoption rates are still unsatisfactory with a low percentage of BIM users [19]. In this regard, in order to determine the level of awareness and implementation of BIM in developing countries, a survey of questionnaires was conducted among a number of construction companies (contractors and consultants) in Iran and Northern Cyprus, the results of which were analyzed. It was found that there was no supply and demand for BIM, since architects and engineers were not properly trained and the owners were not aware of the benefits of BIM. In addition, there was not a single governmental or non-governmental organization that could monitor construction companies and motivate them to implement BIM [20].

However, the benefits of construction technology have not been limited to developed and industrialized countries throughout the history of the construction industry. The diffusion of construction technology from industrialized countries to developing countries 
has long been addressing prominent technological problems in developing countries. Developing countries, on the other hand, share the chronic challenges of the same project delays and overflow costs as industrialized countries. However, to some extent, deep issues have been addressed through the adoption of technology from developed countries such as Auto CAD, software planning and other design programs that have resulted in significant time savings.

Over the past few decades, technology transfer from industrialized countries has focused on lower-level technological development challenges in developing countries. For example, planning software distributed in developed countries has helped construction industries in developing countries develop more reliable and efficient construction schedules and control processes [21]. In this regard, the results of a study by Bui. et. al. (2016), showed that the volume of research on BIM and its use in developing countries is increasing [1].

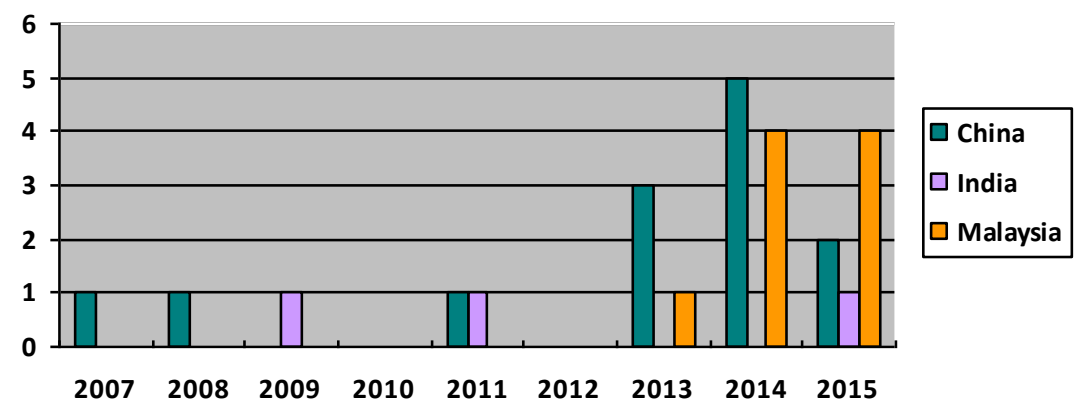

Fig. 1. BIM studies in developing countries.

Although the introduction of technology has helped developing countries alleviate problems, there is still a long list of issues that need immediate attention. Long, etc. al. (2004) found that incompetent designers/contractors, poor valuation, change management, social and technological issues, construction issues, improper methods, and tools are key factors in building problems in Vietnam and other developing countries. In addition, inaccurate time estimates, excessive change orders, lack of resources (including outdated technology), organizational culture and kickbacks, inaccurate cost estimates, poor planning and non-participation, and non-design and impractical design invariably rank as highfrequency emerging problems in the developing construction industry countries [2, 21].

\section{Discussion}

\subsection{CAD and BIM comparison}

Computer-aided design is the process of using computers to assist in the design process of a building, allowing CAD designers to create higher quality paintings more quickly. CAD replaces traditional drafting processes with an automated one. The NBS defines BIM as "a process for creating and managing information on a construction project throughout the project life cycle." This means that modeling is software information that incorporates typical CAD concepts for the design of buildings in a way that incorporates physical and intrinsic building properties [22]. 
In other words, the main difference between BIM and conventional 3D CAD is that the latter describes a building with Independent 3D displays such as plans, Section and elevations. Editing one of these views requires that all other views be reviewed and updated, and the error prone process being one of the main causes of poor documentation [14]. In addition, the data in these 3D maps are only graphical entities, such as lines, bows and circles, as opposed to the contextual meaning of BIM models, in which objects are defined in terms of elements and systems such as spaces., Walls, beams and columns [23].

Building information model carries all building related information, including its physical and functional features and information lifecycle project, in a series of "smart objects". For example, an air conditioning unit in a BIM also includes data on suppliers, operations and maintenance procedures, flow rate and clearance conditions [24]. Also, below, the efficiency of BIM compared to Auto CAD in the Indian industry is shown in Table 2 .

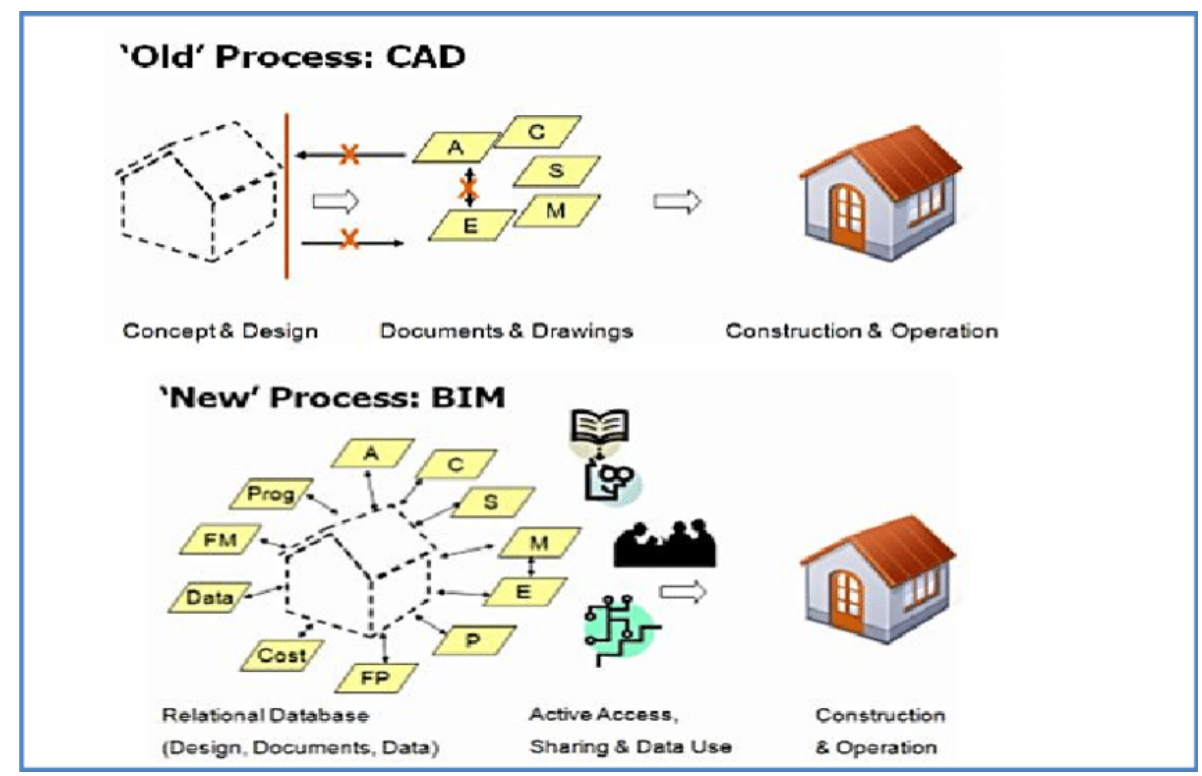

Fig. 2. Comparison between Conventional CAD and BIM Approach.

Table 2. Efficiency difference between CAD and BIM.

\begin{tabular}{|l|c|c|c|c|}
\hline \multicolumn{4}{|c|}{$\begin{array}{l}\text { The Efficiency Difference Between CAD and BIM Applications for Particular } \\
\text { Project in Different Phases }\end{array}$} \\
\hline Task & CAD & BIM & Hours Saved & Time \\
\hline Schematic & 190 & 90 & 100 & $53 \%$ \\
\hline Design Development & 436 & 220 & 216 & $50 \%$ \\
\hline Construction Documents & 1023 & 815 & 208 & $20 \%$ \\
\hline Checking and & 175 & 16 & 159 & $91 \%$ \\
\hline Totals & 1824 & 1141 & 683 & \\
\hline
\end{tabular}

\subsection{BIM as a value creator, not as a cost factor}

The initial costs of BIM can be significant due to the investment required in software, technology infrastructure, consultants and training [25]. Organizations also incur project- 
specific costs for setting up BIM models and changing workflows and team processes. However, companies looking to estimate the financial benefits of BIM often find limited information. This lack of detailed cost-benefit analysis may select some decisions against investment [26]. Figures 2 and 3 show that BIM results in a change in the allocation of resources and costs associated with the early stages of the project. Compared to the traditional 3D CAD approach with BIM, BIM is considered more efficient and less time consuming, so it is less expensive.

\section{Conclusions}

The BIM Using concentrates stakeholder engagement throughout the building's life cycle. At the same time, it provides a central repository of information, which can be accessed by any interested party, when necessary, for the optimal and most efficient use of available information. BIM will only succeed if stakeholders work together to achieve a shared vision based on a common plan. This will allow society to take advantage of the many benefits of BIM, including more accessible infrastructure and housing, a safer and more predictable project implementation, a more sustainable and sustainable environment, and high-quality provision of services to end-users.

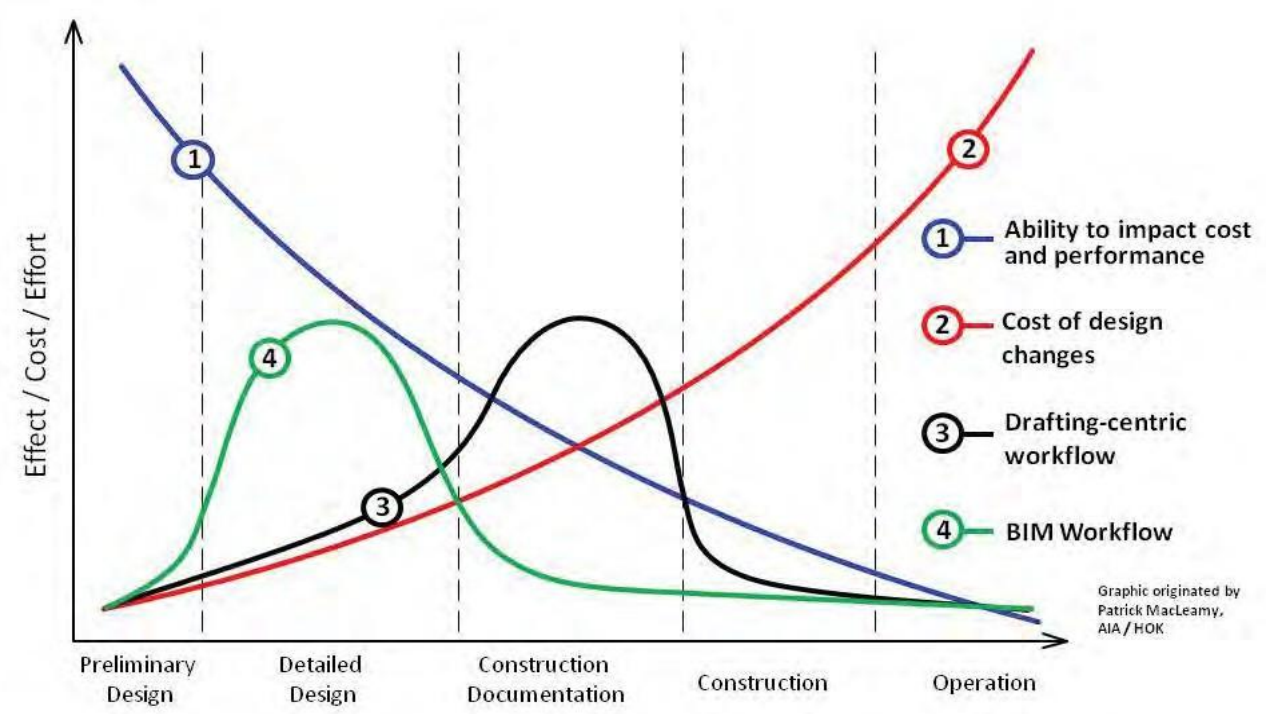

Fig. 3. When using BIM, most of the effort happens during the construction documentation phase when the ability to impact project cost and performance is declining and the cost of making design changes is increasing. 


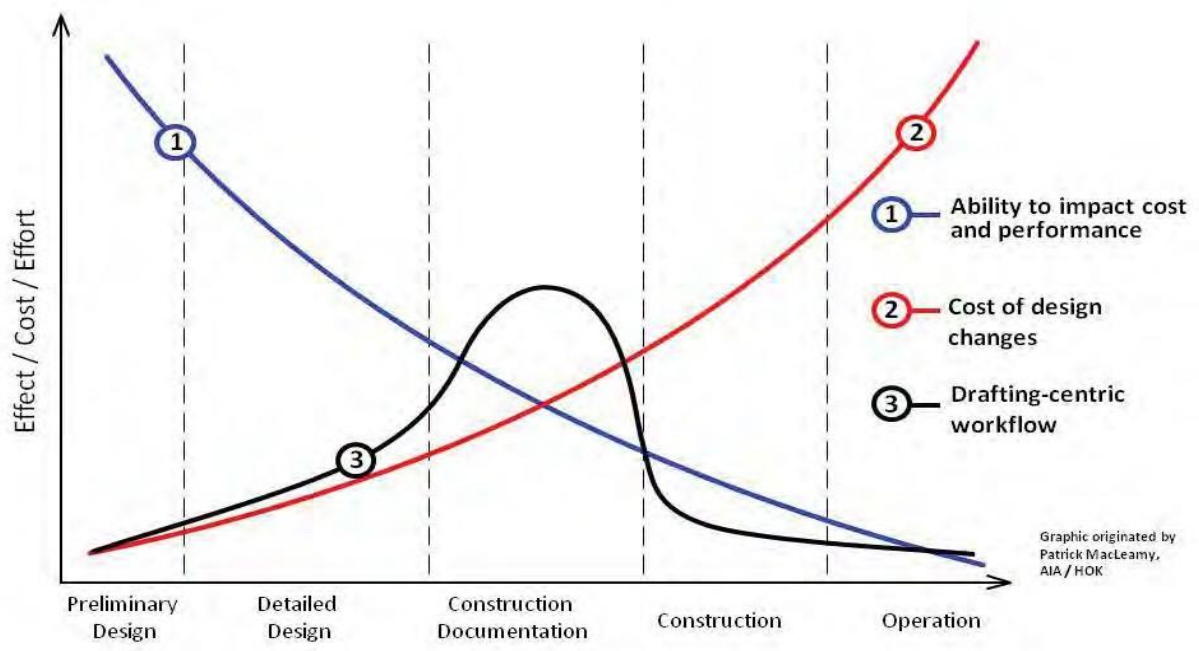

Fig. 4. Using a BIM workflow shifts the level of effort to earlier in the project when the ability to impact project cost and performance is high and the cost of making design changes is low.

\section{References}

1. E. M. Nur, M. S. Rozana, L. B. Hamizah, A. Tajul, International Conference on Research and Innovation in Information Systems (ICRIIS), 1-7 (2017)

2. Associated General Contractors of America, The Contractor's Guide to BIM, 1st ed. (AGC Research Foundation, Las Vegas, NV, 2005)

3. A. N. Boukara, A. Brief, Introduction to Building Information Modeling (2015)

4. A. Borrmann, M. König, C. Koch, J. Beetz, Building Information Modeling (Springer, 2015)

5. S. Azhar, A. Nadeem, Y. N. Johnny, H. Mok, Y. Leung, First International Conference on Construction in Developing Countries (ICCIDC-I) 1, 435-436 (2008)

6. S. L. Fan, J. Miroslaw, W. H. Skibniewski Tsung, Journal of Applied Science and Engineering 17(2), 157-166 (2014)

7. NBIMS, National BIM Standard - United States, Version 3-Scope, 1-5 (2015). https://www.nationalbimstandard.org/

8. S. Azhar, M. Khalfan, T. Maqsood, Australasian Journal of Construction Economics and Building 12 (4), 15-28, (2012)

9. B. Abbasnejad, H. I. Moud, International Journal of Engineering Research and Applications, 2248-9622 (2013)

10. G. Yilmaz, A. Akcamete, O. Demirors, Automation in Construction 101, 245-263 (2019). DOI: 10.1016/j.autcon.2018.10.022

11. M. Marzouk, A. Abdel Aty, Construction research congress (2012), 2320-2328 (2012)

12. N. Bui, C. Merschbrock, B. E. Munkvold, Procedia Engineering 164, 487-494 (2016)

13. R. Kreider, J. Messner, C. Dubler, Proceeding of the 6th International Conference on Innovation in Architecture, Engineering and Constraction,1-10 (2010). http:// bim.psu.edu/uses/Freq-Benefit/BIM_Use-2010_Innovation_in_AEC-

Kreider_Messner_Dubler.pdf 
14. C. Eastman, P. R. Teicholz, K. Sacks, Liston, BIM Handbook, A Guide to Building Information Modeling for Owners, Managers, Designers, Engineers, and Contractors, 978-0-470-54137-1 (2011)

15. H. Y. Chong, C. Y. Lee, X. Wang, J. Clean. Prod. 142, 4114-4126 (2017). DOI: 10.1016/j.jclepro.2016.09.222.

16. H. Yan, P. Damian, Benefits and barriers of building information modelling, The 12th International conference on computing in civil and building engineering (2008)

17. K. D. Andy, K. W. Wong Francis, N. Wong Abid, Architectural Engineering and Design Management 6, 288- 302 (2010)

18. D. J. Gibbs, S. Emmitt, W. Lord, K. Ruikar, BIM and Construction Contracts CPC 2013 's Approach (2013)

19. A. I. N. Akmal, M. Chiozzi, R. Drogemuller, AIP Conference Proceedings 1903, 080008 (2017). DOI: 10.1063/1.5011596

20. N. S. Sistani, A. Rezaei, BIM Implementation in Developing Countries, 10th International Congress on Advances in Civil Engineering (2012)

21. N. D. Long, S. Ogunlana, T. Quang, K. C. Lam, International Journal of project management 22 (7), 553-561 (2004)

22. S. Azhar, Leadership and Management in Engineering 11(3), 241-252 (2011)

23. CRC Construction Innovation, Adopting BIM for Facilities Management: Solutions for Managing the Sydney Opera House, Cooperative Research Center for Construction Innovation (Brisbane, Australia, 2007)

24. J. V. Kumar, M. Mukherjee, Journal of Engineering Science and Technology Review 2(1), 165-169 (2009)

25. W. S. Lu, Y. Peng, Q. Shen, H. Li, ASCE 139(2), 195-203 (2013)

26. W. Lu, F. Ada, P. Yi , L. Cong, S. Rowlinson, Building and Environment 82, 317-327 (2014) 